\title{
Research on the Development Strategy of Internet Banking such as WeBank under the COVID-19
}

\author{
Yi Wang \\ School of Economics and Management, Zhaoqing University
}

\begin{abstract}
Under the background of the "new normal" due to COVID-19, there is an increasing demand for contactless financial solutions. At the same time, with the effective control of COVID-19 in China, the financial needs of small and micro businesses after the recovery of production has also continued to increase. Based on this, as an emerging industry, online banking has become the focus of common concern. WebBank is the first and currently largest Internet private bank in China. Taking WebBank as an example, this paper analyzed the development strategies of online banking, using the PEST analysis method and Porter's five-force model to analyze the external macro-environment, industry competition environment, and internal advantages and disadvantages of the company in detail, and proposed corresponding safeguard measures to provide ideas for the development of other online banks.
\end{abstract}

Keywords: Internet banking, WeBank, Development strategy, COVID-19.

\section{Introduction}

With the rapid development of Internet technology, Internet finance, and the introduction of the "Internet + " plan, China Internet Banking came into being [1]. As an emerging industry, China's first Internet Bank Shenzhen Qianhai WeBank (WeBank) was born at the end of 2014 [2]. At present, the emergence and maturity of mobile payment, Internet of Things technology, cloud computing and big data have also intensified the integration of the emerging Internet industry with the traditional financial industry. There are still different opinions and opinions on the concept and operating model of Internet Banking. In just a few years of development, the development models of various Internet Banks are also being explored. In particular, the outbreak of COVID19 has had a strong impact on the social and economic environment of mankind, and is gradually changing people's lives and consumption habits. People's demand for noncontact in life is becoming stronger. It is foreseeable that there is still space for the development of Internet Banking in China in the future [3], and the competition between traditional commercial banks and Internet Banks, and Internet Banks will become more intense.

As Chinese first Internet private bank, WeBank has attracted much attention since its establishment due to its special Internet genes. In the development process, it has always maintained its position as an industry leader. However, how to continue to develop in the face of the new social and economic environment is a question that needs to be explored. This article attempts to analyze the external environment and internal conditions of WeBank to choose a development strategy suitable for the company. Through the analysis of development strategy, can help WeBank understand the current industry development situation, scientifically integrate existing resource advantages, clarify the development direction, and gradually improve core competitiveness in order to maintain its leading position in the ever-increasing industry competition.

The research has both theoretical and practical significance. On the one hand, by combining the strategic management theory with the actual situation of the first domestic online bank, using PEST Analysis [4], Porter's five forces model, SWOT analysis [5] and other theories to analyze the enterprise, it is the market positioning and development strategy of the network bank. A discussion of theory is also a supplement and improvement to the strategic management theory of Internet Banking, and has certain theoretical significance. On the other hand, with the rapid growth of borrowing demand and the accelerated development of traditional commercial banks' digitalization, online banking is facing the coexistence of opportunities and challenges, and the research on market positioning and development strategies is more practical.

As a new thing that was born in the 1990s, Internet Banking has attracted the attention of domestic and foreign scholars [6]. The current research on Internet Banking mainly includes three aspects: the connotation and characteristics of Internet Banking, the analysis of the reasons for the development of Internet Banking, and the development strategy of Internet Banking [7]. At the same time, people are more concerned about the future development trend of Internet Banking and the countermeasures of traditional banks.

Regarding Internet Banking risks, because Internet Banking has the network attributes of the Internet and the financial attributes of banks, the main risks of Internet Banking can be attributed to Internet security risks and business risks, which are specifically expressed as technical security risks and business operation risks [8]. Correspondingly, the risk control of online banking should include four aspects: technical risk control, internal risk control, risk control for network suppliers, and risk control for consumers[9]. The most important parts in the development of online banking business are security. Online banking must innovate in strengthening management and improving the technical level of online product transaction systems to ensure the bank's own network security and protect the interests of users.

This article adopts theoretical and qualitative analysis methods for research. On the basis of strategic theory, this article investigates WeBank to fully understand the development history, operation mode and internal resources of WeBank, which provides support for accurately summarizing the company's strengths and weaknesses, and 
provides support for the company. The correctness and accuracy of data and literature are ensured by consulting relevant literature, and at the same time, the published data is quoted, supplemented by qualitative analysis in the form of graphs, and using PEST, five forces model, SWOT and other tools to analyze the strategy to ensure success. Make rational analysis and conclusions. These factors not only have a direct impact on the development of the company and the industry, but also have an indirect impact on the production enterprise by affecting suppliers and customers.

\section{Analysis of the External Environment of the Enterprise}

\subsection{Macro Environmental Analysis}

\subsubsection{Political environment}

The Chinese government began to allow private enterprises to spontaneously establish financial institutions that bear their own risks at 2013, including private banks [10]. This means that in China, private companies are also eligible to enter the banking industry. Since then, private capital began to pour into the banking industry. In 2015, the Chinese government proposed the "Internet +" plan in the government work report to support the development of mobile Internet and encourage the healthy development of Internet finance, hoping to promote the integration of Internet technology and traditional financial industry and promote the healthy development of Internet finance. Guide Internet companies to enter the international market. Since then, encouraging policies on Internet finance have been gradually introduced throughout the country. In the same year, Internet finance was included in China's 13th Five-Year Plan for the first time, elevating Internet Banking to a level where government work will be vigorously developed in the future. Under the impact of COVID-19 in 2020, fighting COVID-19, resuming work and resuming production and restoring the economy have become the themes of the world. The online banking, which was born under the Chinese government's expectation of solving the financial problems of small, medium and micro customers, will be given more weight at this historical stage. In particular, the General Office of the State Council of China issued the "Implementation Opinions on Responding to the Impact of the COVID-19 and Strengthening Measures to Stabilize Employment", mentioning that the Chinese government supports multi-channel flexible employment in 2020 and reasonably establishes a management model for vendors with no fixed business premises.

"The street-stall and small-store economy is an important source of employment and human culinary culture-it's part of China's livelihood just as much as larger, high-end businesses", Premier Li Keqiang said. After that, China's "the street-stall economy" has become a hot spot. The street-stall economy refers to an economic form formed by obtaining a source of income through stalls. Many places have issued policies to clearly encourage the development of a "the street-stall economy". Since the introduction of the policy in March to allow vendors to temporarily occupy roads for business operations, as of May 21, 2020, only one city in Chengdu has added more than 100,000 jobs. The economic entities of the street-stall economy are scattered individuals and families, which are the "longtail" customers that Internet Banks pay attention to. The rapid increase in customer base provides a good foundation for the development of Internet Banking.

\subsubsection{Economic environment}

SMEs contribute more than $50 \%$ of China's tax revenue, more than $60 \%$ of GDP, more than $80 \%$ of urban labor employment, and more than $90 \%$ of the number of enterprises. However, due to the small loan lines, insufficient mortgages, and high risks of small and micro enterprises, the proportion of financial support provided by traditional banks is very low. The simplification of the financial system restricts the financing and loans of Chinese SMEs, which is not conducive to the development of SMEs. Therefore, there is an urgent need for the emergence of financial institutions that can meet the funding needs of SMEs. Internet Banking has its own advantages just to meet market demand. Under the impact of COVID-19, small and micro enterprises and individuals with weak anti-risk capabilities have even stronger demand for funds, and the demand for "longtail customers" has increased. The resumption of work and production of the longtail customer base also requires continued financial assistance from online banks.

Driven by the "street-stall economy", many families and even employees will take to the streets in their spare time to start a "small-store economy" to subsidize their families. The activity of the street-stall economy like the mobilization of the whole people stimulates economic development. At the same time, because individuals and families with small businesses and not very strong economic capacity carry out economic activities, they increase the demand for capital turnover and drive the development of lending. These "small and micro customers" are also the main customers of online banking.

\subsubsection{Social environment}

In 2019, the national per capita disposable income of residents was RMB 30,733, an increase of $8.9 \%$ over the previous year, and the per capita disposable income of urban residents reached RMB 42,359. Many residents need to find safe and convenient channels for investment and financial management. It can be said that Internet Banking was created in response to the market driven by strong market demand. At the same time, the number of Chinese Internet users exceeded 900 million, and the number of mobile Internet users reached 897 million. The proportion of Internet users using mobile phones to access the Internet reached $99.3 \%$. As of March 2020, the average weekly online time of Chinese netizens is 30.8 hours. Affected by COVID-19 in early 2020, the online time of netizens has increased significantly, an increase of 3.2 hours from the end of 2018. In addition, as the uncertainty of COVID-19 continues to grow, more and more people are more inclined to choose a contactless lifestyle, such as online shopping and online government affairs. The online demand for banks has also increased accordingly. It can be said that COVID-19 has changed people's lifestyles to a certain extent, and this has laid a good user base for the development of Internet Banking.

With the gradual liberalization of China's financial controls, 
with China's huge population base, growing financing needs, and outdated traditional banking services, P2P network lending financial services have been promoted in China, and they have achieved explosive growth and achieved rapid development. Has absorbed a lot of private deposits, and seized a lot of market share in lending. However, since 2018, P2P defaults have soared, and the scale of P2P defaults in Shanghai alone has exceeded 200 billion. People gradually lose confidence in P2P. As a bank, WeBank, which is based on Tencent, has become one of the investments and financial management objects that people are willing to trust.

\subsubsection{Technical environment}

The new generation of network information technology continues to innovate and make breakthroughs, and the digitization, networking and intelligence are developing in depth, and the world economy is transforming to digital. In the current trend of big data technology, all walks of life are constantly exploring how to apply big data technology to solve the problems faced by enterprises. Relying on smart phones and the Internet, financial technology combines big data, cloud computing, artificial intelligence, Blockchain and other technologies to integrate and change people's lives. The further in-depth and development of Internet finance on the basis of "Internet transforming traditional industries" and "Internet +" has brought new engines and new impetus to the entire financial industry. At present, many financial institutions have begun to try to use big data to drive related financial business operations. The term "financial technology" was mentioned more than 130 times in the annual reports of China's six major state-owned banks in the past two years. As an application scenario of Internet financial technology, Internet Banking has increasingly become the focus of attention. However, commercial banks have obvious shortcomings in frontier science and technology, and the development of financial technology by commercial banks is mainly for the construction and operation of the banking system. In addition, commercial banks have fewer active innovations and a longer innovation cycle. There are obvious shortcomings in R\&D and application capabilities.

\subsection{Industry Environment Analysis}

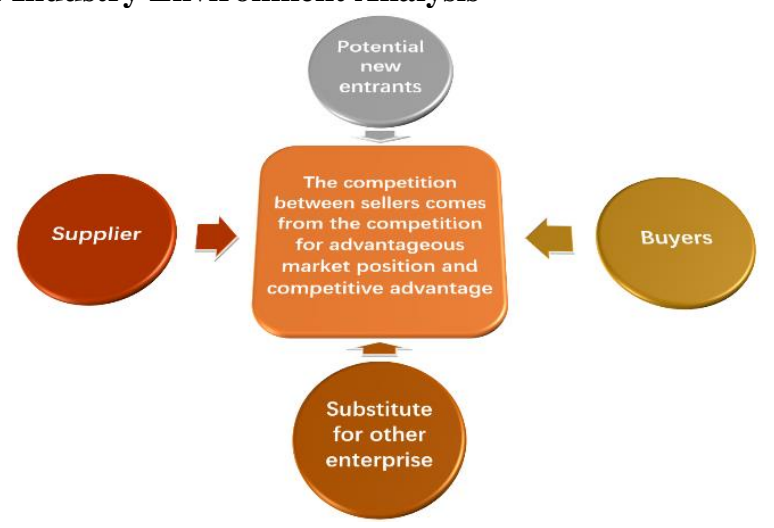

Figure 1: The five basic competitive forces

We analyze the five forces model of WeBank. The five basic competitive forces (see Figure 1) refer to the competition between potential entrants, substitutes, buyers, suppliers and existing competitors in the industry, and the interaction between them. Michael Porter proposed three general strategies, namely cost leadership strategy, differentiation strategy, and focus strategy.

From the perspective of potential new entrants, the impact of potential entrants including both traditional commercial banks and Internet companies, especially direct selling banks, will be huge. In November 2015, China's Internet giant Baidu and China CITIC Bank announced the establishment of a bank, but it operated as a direct bank. It can be said that there are many potential entrants to Internet Banking and the competition is fierce. However, due to the high barriers to entry in the banking industry, potential new entrants are not dominant, and there will be no major threat in the short term. From the perspective of suppliers, as a bank, its suppliers are mainly depositors. As an emerging business, Internet Banking is also dominated by individuals and SMEs. Compared with scattered depositors, WeBank's position as an industry leader enables it to have stronger bargaining power. In terms of negotiating capabilities with buyers, WeBank's customer groups are mainly individuals or small and micro enterprises who cannot obtain traditional bank loans. This group has a large number of individual loan funds with a small demand, but requires a short time. In addition, the amount and conditions for obtaining loans are determined by their behavior on the credit reporting platform. Buyers often have very high loyalty. Therefore, WeBank has strong bargaining power for buyers. In addition, WeBank relies on Tencent's WeChat and QQ, integrates resources, provides better services, and has a complementary product market with a large number of users. The interaction between the two has formed a good ecological cycle and therefore has strong bargaining power. From the perspective of alternatives, because WeBank has the massive data and big data technology advantages of big data provided by Tencent, it can provide more convenient loans without guarantee, and the relative loan amount is also higher. Its main alternative is Ali's online merchant bank. In addition, its alternatives include direct banking, various digital financial services of traditional commercial banks, and even various financial platforms, lending platforms, and so on. However, compared with the direct banking of traditional commercial banks, Weizhong Bank's Weizhongdai and Antboraibo both have the advantages of low loan interest rates, low loan requirements, and convenient and quick loan procedures. However, traditional commercial banks have a long history in China, with a huge customer base and reputation, and in the online banking industry, there is a strong rival of online merchant banks. Although WeBank is currently in the leading position in the industry, it is still in the market. Can't be called a dominance.

In summary (see Table 1), it can be seen that the external environment of WeBank is relatively optimistic and the environmental pressure is not too great. But whether it can continue to maintain its leading position in the industry, both opportunities and challenges are emphasized.

Table 1: Michael Porter's five forces model of WeBank

\begin{tabular}{|c|c|}
\hline Model & Evaluation \\
\hline Threat of New Entrants & Higher \\
\hline Rivalry & Lower \\
\hline Bargaining Power of Buyers & Low \\
\hline Bargaining Power of Suppliers & Low \\
\hline Substitutes & High \\
\hline Conclusion & Lower external environmental pressure \\
\hline
\end{tabular}




\section{Analysis of Enterprise Internal Conditions}

\subsection{Basic Situation of the Company}

WeBank was initiated and established by well-known private enterprises such as Tencent, Baiyeyuan and Liye Group, with a registered capital of RMB 3 billion. It was approved to open by regulatory authorities in December 2014 and is headquartered in Shenzhen, Guangdong Province, China. It is China's first private bank and Internet Bank. Tencent subscribes for $30 \%$ of the bank's total capital stock and is the largest shareholder.

The bank has neither business outlets nor business counters, nor does it require property guarantees. Instead, it issues loans through facial recognition technology and big data credit ratings. The main business covers consumer finance, mass financial management, platform finance, etc. Its characteristic product "Micro Loan" is Chinese the first domestic loan product that realizes the entire process from application, approval to lending to realize online online operations on the Internet, with unique highlights of inclusiveness and convenience. "Micro Loan" relies on Tencent's two major social platforms QQ and WeChat, without guarantee, no mortgage, and no application; customers only need their name, ID card and phone number to get a credit line; the limit is set at 500 to 200,000 yuan. It can meet the small consumption and business needs of the general public. Use Internet technology to reach a large number of users, and extend extremely convenient banking services to low income groups that traditional banks cannot cover. On October 21, 2019, Hurun Research Institute released the "2019 Hurun Global Unicorn List", and WeBank ranked 11th. On January 9, 2020, the Hurun Research Institute released the "2019 Hurun China Top 500 Private Enterprises", and WeBank ranked 36th with a market value of 150 billion yuan.

\subsection{The company's core competitiveness}

The core competitiveness of WeBank is manifested in its excellent technology research and development capabilities, financial capabilities, cost control capabilities and human resources capabilities.

\subsubsection{Technology research and development capabilities}

Since its establishment five years ago, WeBank has continued to carry out technological breakthroughs in the research and application of the underlying algorithms of key core technologies such as Blockchain, artificial intelligence, big data and cloud computing. It has independently researched and developed federated learning artificial intelligence algorithms and led the development of blocks FISCO BCOS, the underlying platform of the chain, has been open source successively. In 2019, research and development expenses accounted for nearly $10 \%$ of operating income.

In 2019, there were 632 invention patent applications published, and the number of Blockchain invention patent applications alone reached 217, ranking fifth in the world. WeBank has joined hands with leading domestic technology companies to continue to advance the research $\mathrm{h}$ and development of safe, reliable and advanced chip technology with completely independent intellectual property rights, and successfully realize the largescale production and deployment of related chips and servers; distribution with completely independent intellectual property rights The core banking system has successfully served more than 200 million customers, achieved an average of 360 million daily transactions, with a peak of nearly 600 million transactions per day; it has achieved the scale of the first-tier bank in China, significantly reducing the operation and maintenance cost per account. WeBank has fully open-sourced its main technological achievements at home and abroad, and has gradually transformed from beneficiaries of open source technologies to contributors, and actively provides infrastructure for several industries and their competent departments, assists in the creation of technological ecology and establishes industry standards, trying to become an industry standard setter.

\subsubsection{Cost control ability}

The cost control capability of WeBank makes it possible for WeBank to serve a large number of small and micro customers. In the process of using financial technology, WeBank emphasizes the principle of "three ups and two downs", that is, through technological means to improve financial efficiency, improve customer experience, and provide services for mass production and scale; at the same time, it can reduce service costs and control Risk. The characteristic approach of reducing costs with technology and demanding benefits from technology enabled WeBank to continue to benefit customers. The interest rate on new loans issued throughout the year decreased by 1.84 percentage points from the previous year, and the average profit contribution per household was less than 20 yuan.

\subsubsection{Human resource capacity}

WeBank has a professional senior management team, a huge team of scientific researchers, and a team of elite financial practitioners. Since the establishment in 2014, as far as the management is concerned, most of them are leaders with many years of work experience and industry status in the financial and Internet industries. For example, Chairman $\mathrm{Gu}$ Min has served as an executive director of McKinsey and Pingan Group; President Li Nanqing has a deep government background and served as the Secretary of the Board of Pingan Bank of China; Chief Information Officer Ma Zhitao graduated from Stanford University and worked in major international companies such as Oracle and Hewlett-Packard.

In 2019, WeBank's technology personnel accounted for nearly $60 \%$, and we focused on the formation of a professional technology team with multilingual and multicultural adaptability. Team members have work experience in the United States, Singapore, Hong Kong and other places and implementation experience of multinational largescale technology projects. The headquarters of WeBank was established in Shenzhen, the forefront of China's reform and opening up. It is also the headquarters of China Pingan Group and China Merchants Bank. According to data from the Fourth China Economic Census, Shenzhen has the largest number of financial professionals in the country. This provides a very large resource pool for WeBank to select 
candidates. Under the influence of COVID-19, employment has become a worldwide problem. Serving employees generally do not easily choose to leave in this economic environment. Staff stability is enhanced.

\subsubsection{Financial capacity}

As of the end of 2019, the number of individual customers served by WeBank exceeded 200 million, an increase of $68 \%$ from the beginning of the year, the number of corporate customers reached 900,000, and the balance of managed loans and assets under management exceeded 440 billion yuan. The annual revenue exceeded 14.8 billion yuan, the net profit was 3.95 billion yuan, and the tax payment was 2 billion yuan, achieving a win-win situation for both economic and social benefits. It can be seen from its balance sheet (see Table 2) that the financial situation is in a prosperous state of development. Of the 275 million yuan in liabilities in 2019 , deposits accounted for 237 million, accounting for $86.2 \%$, and the bank's financial status is good.

Table 2: Part of the accounting data and financial indicators of WeBank from 2015 to 2020

\begin{tabular}{|c|c|c|c|c|c|c|}
\hline Operating performance indicators & 2020 & 2019 & 2018 & 2017 & 2016 & 2015 \\
\hline Operating income (million) & 19880.62 & 14870.33 & 10029.74 & 6748.08 & 2449.35 & 225.72 \\
\hline Net profit (million) & 4957.07 & 3949.75 & 2474.13 & 1448.16 & 401.48 & 583.82 \\
\hline Total assets (million yuan) & 346429.99 & 291235.59 & 220036.61 & 81703.68 & 51995.49 & 9620.98 \\
\hline Total liabilities (million yuan) & 325401.92 & 275116.45 & 208096.13 & 73371.82 & 45291.8 & 7194 \\
\hline Net interest margin (\%) & 14.31 & 13.56 & 11.24 & 7.02 & 5.96 & 3.14 \\
\hline Return on Assets(\%) & 10.33 & 8.92 & 6.95 & 2.17 & 1.30 & -9.22 \\
\hline
\end{tabular}

\subsection{Problems and Challenges in Development}

First, it faces the problem of homogeneity of products and services. Due to the wide application of financial technology and the influx of private capital into the banking industry, basically as long as one bank launches a certain product and service, other banks will soon launch the same or similar products and services. For example, WeBank's demand deposits are very similar to Ant-Financial's Yue Bao. Apart from relying on a higher annualized rate of return, it cannot rely on anything else to effectively increase customer retention. The products of current products, fixed-term products, funds and transfer-in and transfer-out services are also very similar to products of other banks in the market.

Second, risk control capabilities need to be strengthened. In terms of the technical sources of risk control, WeBank's big data is more derived from Tencent's social data, which is relatively risky compared with traditional bank credit investigation and Ant-Financial's credit investigation using Taobao's data. The intuition and effectiveness of the evaluation will need more time and data to test. As far as the customer group it serves, as an Internet Bank, most of the credit customers it faces are individuals and small and micro enterprises. The risks and monitoring difficulties are very high. In addition, COVID-19 has increased the credit of individuals and small and micro enterprises. The uncertainty of survival makes WeBank facing greater risks. In terms of risk control capabilities, Chen Yulu, deputy governor of the People's Bank of China, said: The average nonperforming loan ratio of Chinese commercial banks in 2019 was only $1.86 \%$, and the nonperforming loan ratio of SMEs was slightly higher than the average. According to WeBank's 2019 financial report, its nonperforming loan ratio is only $1.24 \%$ (see Table 3 ), which is far below the $5 \%$ regulatory standard and the average level of commercial banks. But we also need to see that WeBank's nonperforming loan ratio has shown a trend of increasing, which has more than doubled.

Table 3: 2015-2019 NPL ratio of WeBank

\begin{tabular}{|c|c|c|c|c|c|}
\hline Category/year & 2009 & 2018 & 2017 & 2016 & 2015 \\
\hline Non-performing loan ratio (\%) & 1.24 & 0.51 & 0.64 & 0.32 & 0.12 \\
\hline
\end{tabular}

WeBank now supports remote account opening for both public and personal customers. However, remote opening of personal accounts is a second-level account, and this type of account has restrictions on usage scenarios and transfer amount cash withdrawal, so it is not as rich as a type of account. Now according to the account policy, upgrading the first-level account must be verified on the spot. This is a policy issue, which cannot be broken for the time being and can only be followed. This means that the customer needs to open a second-level account remotely, and then the customers have to come to WeBank to handle the upgrade of the first-level account on site. For this reason, WeBank also has business office counters open. Remote account opening is supported for public accounts, but there is also a link in the middle that involves onsite verification of empirical documents for background investigation. This is also a policy issue and cannot be broken.

\section{Company Strategy Formulation}

\subsection{Company SWOT Analysis}

\subsubsection{Company internal advantages}

Excellent management team and high-quality human resources are the powerful advantages of the company's development. Backed by Tencent, the ability to fully enjoy Tencent's brand influence and the customer base resources of WeChat and QQ is its unique and inimitable internal advantage. The cost control capability based on leading technology is the guarantee for its continuous improvement of product competitiveness.

\subsubsection{Weaknesses within the company}

The nonperforming loan ratio continues to rise. Although it is still within a safe value, because the bank has only a short five-year history of development, the nonperforming loan ratio may continue to precipitate over time. Affected by the existing system, online banks can only open second-level accounts, which are restricted in usage scenarios and transfer amounts. The usage scenarios are not as rich as those in first-level accounts, which will lose their attractiveness to some users and enhance the bank's preference to other banks. At the beginning of the bank's establishment, most of its employees came from Pingan Group, and a large number of "parachuters" leaders and core technical backbones joined the 
bank. The impact of traditional bank operation philosophy and the development thought of new Internet Bank led to cultural conflicts and collisions, which caused strong pains for the enterprise. This can be seen from the frequent changes of managers in the startup period of Webank.

\subsubsection{External opportunities}

The rapid development of fintech has laid a technical foundation for the development of Internet Banking. With the support of national policies and the strong demand of the public for assured financial products, Internet Banks emerge as The Times require. Especially under the influence of coVID-19, individuals tend to be more conservative in their investment. Compared with various financial platforms, people are more willing to put their money in Banks. Affected by COVID-19, people need more convenient and simple financial services that can be operated remotely. This is exactly the demand that Internet Banking can best meet. Under the impact of COVID-19, small and micro businesses that are already in difficulty in financing need more financial support, and some individuals also need funds due to the impact of COVID-19, which has added momentum to the business of Internet Banking.

\subsubsection{External threats}

The first threat comes from competition from substitutes. The homogeneity of products in the entire industry is serious. In the Internet Banking industry, the most direct competition is the direct competition of Ali's online commercial banks. Although there are other online banks, they are temporarily unable to pose a direct threat to WeBank. In the banking industry, it is necessary to face the competition of electronic services of major commercial banks. For example, major commercial banks in China are mainly promoting mobile APP services and electronic payment services. In the Internet industry, companies with financial technology capabilities are facing competition in the banking sector at any time, such as Baixin Bank jointly established by Baidu and China CITIC Bank. Even face the competition of a large number of mixed $\mathrm{P} 2 \mathrm{P}$ platforms, such as the orange financial management of the listed company Lexin. Under the influence of COVID-19, small and micro enterprises have increased the pressure to survive, increasing the risk of bank loans. Even COVID-19 has an impact on the lives and properties of families and individuals. How to identify customer risks and reduce the rate of nonperforming loans has become a key issue to be considered.

An analysis of WeBank's SWOT strategic portfolio shows that the industry in which WeBank is located has a lot of room for development, with great market potential and great demand. The company is currently in a leading position in the industry. Strategic choices should be based on the use of technological advantages to further occupy the market, accelerate technological and product innovation, and promote largescale development as the main direction. Therefore, companies should take SO strategy as the main strategic orientation. However, we should not pursue market expansion unilaterally during development. We must face external threats, pay particular attention to financial risks, overcome the company's own disadvantages, and value the ST, WO, and
WT portfolio strategies that are beneficial to the company's long-term development, and actively promote countermeasures to ensure Enterprises achieve sustainable development.

\subsection{Cultivate Internet Banking Professionals and Strengthen Team Cohesion}

In China, undergraduate majors such as computational finance, artificial intelligence, data computing and applications were newly added in 2019. Therefore, there are not many talents with both Internet and financial capabilities. Most of the employees of WeBank are Internet industry employees or professional financial employees. Employees with different cultural thinking and different backgrounds need to learn and integrate to become true Internet Banking talents. There are also frictions between internal existing employees and later management employees. The human resources department should strengthen the training and balance between employees with different backgrounds, departments and different periods, improve the incentive and reward model, promote team building, and create employees with multiple backgrounds.

\subsection{Continue to Increase $R \& D$ Investment}

The foundation of Internet Banking is financial technology, which is why WeBank has been able to develop rapidly since its establishment and always maintain its leading position in the industry. Therefore, it is necessary to increase R\&D investment, maintain technological advantages, and continue to widen the gap with other companies. Use technology to promote user experience improvement, use technology to enrich product categories, use technology to ensure financial security, and use technology to ensure the effective implementation of low-cost strategies and differentiation strategies.

\subsection{Strengthen Quality Management}

For Internet Banks, to strengthen quality management, first is to strengthen product service capabilities and service levels. In addition to providing working capital loan products, WeBank has also used financial technology to vigorously expand the two major businesses of supply chain finance and cash management in response to the needs and pain points of small and micro enterprises, and established business cooperation with leading brands in related industries, covering upstream and downstream. Strengthening quality management is not only reflected in products and services, but also in the management of employees. All company actions are completed by employees, and proper employee behavior is an important factor in ensuring operational safety. Priority internal control and compliant operation have always been the value proposition of WeBank.

WeBank links internal control construction with performance appraisal, leading employees to clarify value propositions, and business development and risk prevention and control are based on compliance. At the same time, the abnormal behavior of employees was investigated through supervision and monitoring, strengthened rectification and ensured the effective implementation of internal control. 


\section{Conclusion}

This paper conducts a comprehensive research on the development strategy of China's first Internet Bank WeBank, using PEST Analysis and Porter's five forces model to analyze the company's external macro environment, industry competition environment, and internal advantages and disadvantages. We believe that WeBank currently has development advantages in the political environment, economic environment, social environment and technological environment. The threat of potential entrants and substitutes is high, while the threat of suppliers and buyers is low, and overall external environmental pressure is low. Strong internal technology $R \& D$ capabilities, cost control capabilities, human resources capabilities, and financial capabilities; at the same time, it faces product and service homogeneity issues and risk control issues in the business process, and it also receives the influence and constraints of existing policies during the development process. On the basis of this analysis, we adopted the SWOT Analysis matrix to select WeBank's strategy, and proposed corresponding safeguard measures such as cultivating Internet Banking professionals, strengthening team cohesion, continuously increasing $\mathrm{R} \& \mathrm{D}$ investment, and strengthening quality management. Through the analysis, it is concluded that the overall strategy of WeBank should adopt the strategy of diversifying the main business, increase the expansion of the main business, and attach importance to the expansion of new economic growth points.

In terms of business strategy, cost leadership and differentiation strategies should be adopted. This requires companies to further improve their financial technology capabilities, reduce costs and increase efficiency and innovate products on the basis of ensuring financial security. Differentiation can start from two aspects: product differentiation and service differentiation. Technology is an important guarantee to ensure barriers to differentiation. In terms of functional strategy, technology strategy, talent strategy and brand strategy are adopted. Among them, technology strategy is the focus of corporate strategic development. WeBank needs to continue to increase R\&D investment, ensure product performance and service quality, and ensure technological leadership in the industry, while striving to make its own technology the industry standard to consolidate its leading market position in online banking.

Finally, by strengthening the training of compound talents, strengthening the building of talent teams, improving the incentive and reward model, strengthening quality management, and continuously increasing R\&D investment, the company provides guarantee for the specific implementation of the overall strategy, business strategy and functional strategy. This article does not conduct a comparative analysis of WeBank's main competitor, Internet Merchant Bank. The proposed development strategy lacks the pertinence of the current second-largest Internet Bank, so there are insufficient. In the future, the development strategy can be studied in detail according to the characteristics of competitors.

\section{Acknowledgement}

This research was funded by General University Key Field Special Project of Guangdong Province, China (Grant No. 2020ZDZX3078); General University Characteristic Innovation Project of Guangdong Province, China (Grant No. 2018KTSCX250).

\section{References}

[1] Qiao S, Chang W A, YZ A, et al. Dominant platform capability, symbiotic strategy and the construction of "Internet+ WEEE collection" business ecosystem: A comparative study of two typical cases in China ScienceDirect[J]. Journal of Cleaner Production, 2020, 254: 120074.

[2] Nam E Y, Yi W. The internal resources of Chinese Internet primary banks based on the VRIO framework: A case-study of WeBank[J]. The e-Business Studies, 2020, 21(1): 33-52.

[3] G. Yi, N. M. M. Zainuddin, N. A. B. A. Bakar. Conceptual model on Internet banking acceptance in China with social network influence[J]. International Journal on Informatics Visualization, 2021, 5(2): 177-186.

[4] Sammutbonnici T, Galea D. PEST analysis. 2014.

[5] R. Hidayat, B. Yanuwiadi, B. Prasetyo. A study on the independence of Malang Waste Bank (BSM) based on SWOT analysis[J]. Indonesian Journal of Environment and Sustainable Development, 2017, 8(1).

[6] F. Karen, L. William, N. Daniel. Internet banking[J] Journal of Financial Services Research, 2002, 22(1): 95-117.

[7] E. Viviano, V. Michelangeli. Can Internet Banking affect households' participation in financial markets and financial awareness?[J]. Bank of Italy Temi di Discussione (Working Paper), 2021, 1329.

[8] G. Ramakrishnan. Risk management for internet banking[J]. Information Systems Control Journal, 2001, 6: 48-51.

[9] S. Kaur, S. Arora. Role of perceived risk in online banking and its impact on behavioral intention: Trust as a moderator[J]. Journal of Asia Business Studies, 2020.

[10] K. Davies. China investment policy: An update[M]. OECD Publishing, 2013. 